\title{
Curcumin protects the pancreas from acute pancreatitis via the mitogen-activated protein kinase signaling pathway
}

\author{
YINGJIE WANG $^{1 *}$, CHANYUAN BU $^{1 *}$, KANGKANG WU $^{2}$, RUI WANG $^{1}$ and JIAYONG WANG ${ }^{3}$ \\ ${ }^{1}$ Intensive Care Unit; ${ }^{2}$ Department of Gastroenterology, Qilu Hospital of Shandong University (Qingdao), \\ Qingdao, Shandong 266035; ${ }^{3}$ Department of General Surgery, Qilu Hospital of Shandong University, \\ Jinan, Shandong 250012, P.R. China
}

Received November 21, 2018; Accepted April 15, 2019

DOI: $10.3892 / \mathrm{mmr} .2019 .10547$

\begin{abstract}
Curcumin has been demonstrated to reduce markers of inflammation during acute pancreatitis (AP). However, the underlying mechanisms of the protective effects of curcumin are unknown. In the present study the effects of curcumin in an AP animal model and cell models was examined and the underlying mechanisms were investigated. An AP animal model was established by injection of 5\% sodium taurocholate into the biliopancreatic duct of rats, and the cell model was established by treatment with $0.5 \mathrm{nM}$ cerulein with an optimal concentration of lipopolysaccharide in AR42J rat pancreatic cancer cells. Amylase activity and arterial blood gas composition were assessed by automatic biochemical and blood gas analyzers. Pathological alteration of the pancreas was determined by hematoxylin and eosin staining. Interleukin (IL-6), tumor necrosis factor (TNF)- $\alpha$ and C-reactive protein (CRP) levels were measured by ELISA. Cell viability was determined by Cell Counting Kit- 8 and protein expression levels were assessed by western blotting. Curcumin reduced the ascites volume after 12 and $24 \mathrm{~h}$, the weight of pancreas after 12, 24 and 36 h of surgery, but also attenuated injury to the pancreas. Serum expression levels of TNF- $\alpha$ and CRP were reduced by curcumin. In addition, curcumin decreased the cell viability, amylase activity and the phosphorylation of p38 in AR42J cells, but did not affect the intracellular levels of IL- 6 and TNF- $\alpha$. Curcumin may lower the severity and inflammatory response via the mitogen-activated protein kinase-signaling pathway, to some extent. However, future studies are required to fully understand the protective effects of curcumin on AP.
\end{abstract}

Correspondence to: Dr Jiayong Wang, Department of General Surgery, Qilu Hospital of Shandong University, 107 Wenhuaxi Road, Jinan, Shandong 250012, P.R. China

E-mail: jiayongw_wangjy@163.com

*Contributed equally

Key words: curcumin, acute pancreatitis, mitogen-activated protein kinase, pathology, inflammation

\section{Introduction}

Acute pancreatitis (AP) is a common acute clinical disease, which, if left untreated may be fatal (1). AP can also induce organ failure with systemic inflammatory response syndrome $(2,3)$, and its pathogenesis is not completely understood (2). Accelerated or excessive secretion of pancreatic juices caused by gallstones or overeating, if not excreted in time, will induce the activation of inactive pancreatic enzymes and produce a digestive effect on the autologous pancreas and the surrounding tissues, leading to various effects on the body (4). When AP occurs, the body releases a variety of cytokines and inflammatory mediators such as interleukin (IL)-1, IL-6, IL-8 and tumor necrosis factor (TNF)- $\alpha$ in response to the stimuli, leading directly or indirectly to the inflammatory cascade, stimulating organs and eventually causing acute respiratory distress syndrome (5). Therefore, it is necessary to find a drug that can effectively control the progress of such a disease.

Curcumin is a phenolic pigment extracted from the rhizome of turmeric (6) and possesses anti-inflammatory, antioxidant and anticancer effects (7). Anchi et al (8) demonstrated that sustained-release curcumin decreased the serum amylase and lipase levels, and inflammatory cytokines in cerulein-induced acute pancreatitis. Zhu et al (9) demonstrated that curcumin may protect the kidney from acute renal injury in an AP animal model (9). Therefore, curcumin may be a potential therapeutic option for the treatment of AP; however, the underlying mechanisms of the protective effects of curcumin are not completely understood.

Therefore, the role of curcumin in animal and cell models of AP was investigated. Additionally, the underlying mechanism was also examined to improve our understanding of the therapeutic effects of curcumin. The present study indicated the potential of curcumin in the treatment of AP.

\section{Materials and methods}

Establishment of an animal model of AP and sample collection. The present study was approved by The Ethical Board of Qilu Hospital of Shandong University. A total of 48 12 week-old female Sprague Dawley rats (200-220 g) were purchased from The Model Animal Research Center of Nanjing University. Rats were fed in a climate-controlled room $\left(20 \pm 1^{\circ} \mathrm{C}\right.$ 
at 50\% humidity) under a 12/12 h light/dark cycle and supplied with clean water and food daily. All rats were randomly divided into three groups (Sham, AP and CUR), with 16 rats in each group. For the AP (acute pancreatitis alone) and CUR (acute pancreatitis + curcumin) groups, rats were fasted for $12 \mathrm{~h}$ before the surgery and were anesthetized by intraperitoneal injection of $4 \%$ chloral hydrate at room temperature. A laparotomy in the midline of abdomen was performed. At the level of the hepatic hilum, the biliopancreatic duct was blocked with a vascular clip and cannulated transduodenally with a catheter. A solution of 5\% sodium taurocholate (Sigma-Aldrich; Merck $\mathrm{KGaA} ; 1 \mathrm{ml} / \mathrm{kg}$ of bodyweight) was slowly injected into the biliopancreatic duct. For animals in the Sham group, their biliopancreatic ducts were injected with an equal volume of sterile physiological saline. Animals in the CUR group were acute pancreatitic rats receiving an intraperitoneal injection of curcumin solution (Sigma-Aldrich; Merck KGaA; 200 mg/kg of body weight) dissolved in DMSO immediately after surgery. Subsequently, rats were fed in the climate-controlled environment $4 \mathrm{~h}$ after the surgery. At 12, 24 and $36 \mathrm{~h}$ after surgery, animals were sacrificed by $\mathrm{CO}_{2}$ suffocation separately. Blood, ascites and pancreatic tissues were collected. The weights of the pancreatic tissues were recorded immediately. The ascites were gathered from the abdominal cavity with a syringe and transferred to tubes to immediately measure the volume of ascites.

Assessment of amylase activity and arterial blood gas (ABG). The partial pressure $(\mathrm{Pa}) \mathrm{O}_{2}$ and $\mathrm{PaCO}_{2}$, and the serum amylase activity, were measured by taking blood samples from the abdominal aorta. Samples were centrifuged at 3,000 x g for $5 \mathrm{~min}$ at $4^{\circ} \mathrm{C}$. The supernatant was collected and stored at $-80^{\circ} \mathrm{C}$. The amylase activity of the serum and AR42J cells was determined by the G7-PNP method (amylase activity assay kit; MAK009-1KT; Sigma-Aldrich; Merck KGaA) using a 7600 automatic biochemical analyzer (Hitachi, Ltd.). The $\mathrm{PaO}_{2}$ and $\mathrm{PaCO}_{2}$ in serum were analyzed by an ABL80 automatic blood gas analyzer (Radiometer Medical ApS).

Hematoxylin and eosin staining. Pancreatic tissues were fixed with $4 \%$ formaldehyde at room temperature for $2 \mathrm{~h}$ after sampling. Tissues were cut into $1 \mathrm{~cm} \mathrm{x1} \mathrm{cm} \mathrm{x1} \mathrm{cm} \mathrm{cubes} \mathrm{and}$ embedded in paraffin and further cut into sections (thickness, $5 \mu \mathrm{m})$ and mounted onto slides. The sections were dewaxed as follows: i) $5 \mathrm{~min}$ in xylene I; ii) $5 \mathrm{~min}$ in xylene II; iii) $5 \mathrm{~min}$ in absolute ethanol I; $5 \mathrm{~min}$ in absolute ethanol II; iv) $5 \mathrm{~min}$ in $95 \%$ ethanol; v) 2 min in $90 \%$ ethanol; vi) 2 min in $80 \%$ ethanol; vii) $2 \mathrm{~min}$ in $70 \%$ ethanol; and viii) $2 \mathrm{~min}$ in distilled water. The sections were stained with hematoxylin and eosin as follows: i) Stained with hematoxylin for $10 \mathrm{~min}$; ii) washed with distilled water for $1 \mathrm{~min}$; iii) placed in $1 \%$ acidic alcohol differentiation for $5 \mathrm{sec}$; iv) washed with distilled water for $1 \mathrm{~min}$; v) placed in $0.2 \%$ ammonia for $30 \mathrm{sec}$; vi) washed with distilled water for $1 \mathrm{~min}$; vii) stained with eosin for $5 \mathrm{~min}$; and viii) washed with distilled water for $30 \mathrm{sec}$. All steps were performed at room temperature. The sections were then sealed with neutral balsam and observed under a light microscope (magnification, x100 and x200).

Cell culture and modeling. The AR42J rat acinar cell line was purchased from the Type Culture Collection of the
Chinese Academy of Sciences, and cultured in RPMI-1640 medium (Thermo Fisher Scientific, Inc.) supplemented with 10\% FBS (Thermo Fisher Scientific, Inc.). Cerulein (CR; cat. no. C9026) and lipopolysaccharide (LPS; cat. no. L2630) were both purchased from Sigma-Aldrich (Merck KGaA) and were used to mimic AP in the AR42J cells. The cells were cultured in flasks at $37^{\circ} \mathrm{C}$ with $5 \% \mathrm{CO}_{2}$ and passaged every $2-3$ days. To optimize the AP cell modeling, the cells were treated as follows: i) Medium only; ii) $0.5 \mathrm{nM} \mathrm{CR}$ and $0.1 \mu \mathrm{g} / \mathrm{ml} \mathrm{LPS}$; iii) $0.5 \mu \mathrm{g} / \mathrm{ml}$ LPS; iv) $1.0 \mu \mathrm{g} / \mathrm{ml} \mathrm{LPS}$; v) $0.5 \mathrm{nM}$ CR and $0.1 \mu \mathrm{g} / \mathrm{ml} \mathrm{LPS}$; v) $0.5 \mathrm{nMCR}$ and $0.5 \mu \mathrm{g} / \mathrm{ml} \mathrm{LPS}$; and vi) $0.5 \mathrm{nM}$ CR and $1.0 \mu \mathrm{g} / \mathrm{ml} \mathrm{LPS}$, and termed the Blank, CR, LPS 0.1, LPS 0.5, LPS 1, CR + LPS 0.1 and CR + LPS 0.5 and CR + LPS 1 groups, respectively. To investigate the role of curcumin, the cells were treated with either: i) Medium only; ii) $0.5 \mathrm{nM}$ CR with $1.0 \mu \mathrm{g} / \mathrm{ml} \mathrm{LPS}$; iii) $2.5 \mathrm{mg} / 1$ curcumin; iv) $5 \mathrm{mg} / 1$ curcumin; v) $10 \mathrm{mg} / \mathrm{l}$ curcumin; vi) $2.5 \mathrm{mg} / \mathrm{l}$ curcumin, $0.5 \mathrm{nM}$ $\mathrm{CR}$ and $1.0 \mu \mathrm{g} / \mathrm{ml} \mathrm{LPS}$; vii) $5 \mathrm{mg} / 1$ curcumin, $0.5 \mathrm{nM} \mathrm{CR}$ and $1.0 \mu \mathrm{g} / \mathrm{ml} \mathrm{LPS}$; and viii) $10 \mathrm{mg} / 1$ curcumin, $0.5 \mathrm{nM} \mathrm{CR}$ and $1.0 \mu \mathrm{g} / \mathrm{ml}$ LPS, and were termed the Blank, CR + LPS, CUR 2.5, CUR 5, CUR 10, CUR 2.5 + CR + LPS, CUR $5+$ CR + LPS and CUR $10+$ CR + LPS groups, respectively.

Measurement of $I L-6, T N F-\alpha$ and $C$-reactive protein $(C R P)$ levels. The rat IL-6 ELISA kit (cat. no. RAB0311-1KT) rat TNF- $\alpha$ ELISA kit (cat. no. RAB0480-1KT) and rat CRP ELISA kit (cat. no. RAB0097-1KT) were all purchased from Sigma-Aldrich (Merck KGaA) and were used to measure the levels of IL-6, TNF- $\alpha$ and CRP, respectively, in the serum of rats or in AR42J cells.

Cell Counting Kit $8(C C K-8)$ assay. Cell viability was tested using a CCK-8 assay (MedChemExpress). A total of $4 \times 10^{4}$ AR42J cells/well were plated in a 96-well plate in RPMI-1640 medium. The cells were incubated in a $\mathrm{CO}_{2}$ incubator at $37^{\circ} \mathrm{C}$ for $24 \mathrm{~h}$, after which time the cells were further mixed with $10 \mu \mathrm{l}$ CCK-8 solution, according to the manufacturer's protocol, and further incubated in the incubator for $60 \mathrm{~min}$. The optical density (OD) values of wells were read at $450 \mathrm{~nm}$ using a Multiskan ${ }^{\mathrm{TM}}$ microplate reader (Thermo Fisher Scientific, Inc.).

Western blotting. AR42J cells were lysed in RIPA buffer (Beyotime Institute of Biotechnology), according to the manufacturer's protocol (Thermo Fisher Scientific, Inc.) (10), and centrifuged at $4^{\circ} \mathrm{C}$ at $16,000 \times \mathrm{g}$ for $30 \mathrm{~min}$. The protein concentration was measured using a bicinchoninic acid protein assay kit (Beyotime Institute of Biotechnology). The proteins (20 $\mu \mathrm{g} /$ lane) were resolved using a 10\% SDS-PAGE for $100 \mathrm{~min}$ at $100 \mathrm{~V}$. Subsequently, the proteins were transferred to a PVDF membrane for $20 \mathrm{~min}$ at $80 \mathrm{~V}$, followed by washing the membrane PBS with $0.2 \%$ Tween-20 (PBST) three times, and blocking with $5 \%$ non-fat milk for $1 \mathrm{~h}$ at room temperature. The membranes were incubated with the following primary antibodies: i) Anti-p38 (phospho T180 + Y182) antibody (cat. no. ab4822); ii) anti-p38 antibody (cat. no. ab170099); or iii) anti-GAPDH antibody (cat. no. ab9485), all at a 1:500 dilution at $4^{\circ} \mathrm{C}$ in a shaker overnight. The membranes were washed three times with PBST and incubated with a immunoglobulin $\mathrm{G} \mathrm{H}+\mathrm{L}-$ horseradish peroxidase-conjugated secondary 
antibody (cat. no. ab6721; 1:2,000) for $1 \mathrm{~h}$ at room temperature. All antibodies used for western blotting were purchased from Abcam. To visualize the signals, $150 \mu 1$ Pierce $^{\mathrm{TM}}$ enhanced chemiluminescence western blotting substrate (Thermo Fisher Scientific, Inc.) was added for $1 \mathrm{~min}$. Membranes were visualized using a ChemiDoc MP (Bio-Rad Laboratories, Inc.). The gray levels of the blots were measured using ImageJ (version 1.42; National Institutes of Health). GAPDH served as an internal control.

Statistical analysis. Data are presented as the mean \pm SD from three independent experiments. Differences between groups were analyzed using one-way ANOVA followed by Bonferroni's post hoc test. Analysis was performed using SPSS version 16.0 (SPSS, Inc.). $\mathrm{P}<0.05$ was considered to indicate a statistically significant.

\section{Results}

Curcumin reduces the severity of $A P$. To determine whether the severity of AP was attenuated by curcumin, alterations of several hallmarks representing the severity of AP, as well as the pathology of the pancreas from the rats, were examined. The volume of ascites in the AP group was significantly larger compared with the Sham group 12, 24 and $36 \mathrm{~h}$ after the surgery (Fig. 1A; $\mathrm{P}<0.01$ ). The ascites volume in the curcumin group was decreased compared with the AP group at 12 and $24 \mathrm{~h}$ after the surgery $(\mathrm{P}<0.05)$, although there was no significant difference between the curcumin and AP groups at $36 \mathrm{~h}$ after surgery (Fig. 1A).

The $\mathrm{PaO}_{2}$ level in the AP group was lower compared with the Sham group $(\mathrm{P}<0.05)$ and the $\mathrm{PaCO}_{2}$ in the AP group was elevated compared to the Sham group (Fig. 1B; $\mathrm{P}<0.05$ ). However, there was no significant difference between the curcumin and AP groups in terms of $\mathrm{PaO}_{2}$ or $\mathrm{PaCO}_{2}$ level (Fig. 1B).

Similarly, the amylase in the AP group was significantly higher compared with Sham group at 12, 24 and $36 \mathrm{~h}$ after surgery $(\mathrm{P}<0.01)$; however, there was no significant difference between the curcumin and AP groups (Fig. 1C). The weight of the pancreas in the AP group was significantly heavier in the Sham group at 24 and $36 \mathrm{~h}$ after surgery $(\mathrm{P}<0.01)$, and the weight was significantly lighter in the curcumin group compared with the AP group at all time points $(\mathrm{P}<0.01$; Fig. 1D). As presented in Fig. 1E, the hematoxylin and eosin staining demonstrated that there was no observable necrosis of acinar cells in the Sham group, which had clear lobular and interstitial structures, with no notable infiltration of inflammatory cells apart from a few edematous acinar cells (Fig. 1E). The acinar cells in the AP group were swollen and flaky with a disordered lobular structure, and a notably larger number of inflammatory cells. There was also a large amount of inflammatory exudation in the pancreas tissue in the widened and ruptured interstitial space and microvessels, with a large number of overflowing erythrocytes (Fig. 1E). The acinar cells in the curcumin group were edematous, but the pancreas also displayed a widened and edematous interstitial space. Necrosis of acinar cells, infiltration of a large number of inflammatory cells, inflammatory exudation between the lobes and microvascular rupture, as well as the effusion of erythrocytes, were also seen in the pancreas tissue; however, these pathological changes were notably reduced compared with the AP group (Fig. 1E). Taken together, the results demonstrated that curcumin may reduce the severity of AP.

Curcumin reduces the inflammatory response in an animal model of $A P$. To determine whether the inflammatory response was affected by curcumin, the levels of IL- 6, CRP and TNF- $\alpha$ were measured by ELISA. The levels of IL- 6 and TNF- $\alpha$ in the AP group were significantly higher compared with the Sham group, whereas the TNF- $\alpha$ level in the curcumin group was significantly lower compared with the AP group (all $\mathrm{P}<0.01$; Fig. 2A). However, there was no significant difference in the levels of IL- 6 between the AP and curcumin groups (Fig. 2A). Furthermore, CRP levels in the AP group were significantly higher compared with both the Sham and curcumin groups $(\mathrm{P}<0.01$; Fig. 2B), indicating that the inflammatory response was reduced due to the treatment with curcumin in the AP model.

Curcumin reduces cell viability and downregulates amylase activity in AR42J cells. To further determine the effect of curcumin on AP, an AR42J cell line based model was established by treating with cells with CR and LPS. The cell viability and amylase activity were measured in addition to the levels of IL- 6 and TNF- $\alpha$. Cell viability was decreased when the cells were treated with $20 \mathrm{mg} / \mathrm{l}$ curcumin, compared to the cells without treatment (Fig. 3A; $\mathrm{P}<0.01$ ). Furthermore, amylase activity in the $\mathrm{CR}$ group was increased compared with the blank group, and the blank group had reduced amylase activity compared to the CR + LPS $0.1, \mathrm{CR}+\mathrm{LPS} 0.5$ and $\mathrm{CR}+$ LPS 1 groups (Fig. $3 \mathrm{~B} ; \mathrm{P}<0.01$ ). Based on the results presented in Fig. 3B, $1 \mu \mathrm{g} / \mathrm{ml}$ LPS alone had no significant effects on amylase activity. Therefore, $1 \mu \mathrm{g} / \mathrm{ml}$ LPS was used in combination with CR for the establishment of an AP cell model. Amylase activity in the Blank group was significantly decreased compared with the CR + LPS group $(\mathrm{P}<0.01)$, and the CR + LPS group had elevated levels of amylase activity compared to the CUR 2.5 + CR + LPS (P<0.05), CUR $5+$ $\mathrm{CR}+\mathrm{LPS}(\mathrm{P}<0.01)$ and CUR $10+\mathrm{CR}+\mathrm{LPS}$ groups $(\mathrm{P}<0.01$; Fig. 3C). The levels of IL-6 and TNF- $\alpha$ in cells treated with CR + LPS were significantly increased compared with the Blank group, although they did not differ significantly from those in the CR + LPS, CUR $2.5+\mathrm{CR}+\mathrm{LPS}, \mathrm{CUR} 5+\mathrm{CR}+$ LPS or CUR $10+$ CR + LPS groups (Fig. 3D and E; P<0.01). Based on these results, curcumin may attenuate AP in AR42J cells, but did not affect the inflammatory response.

Curcumin downregulates the phosphorylation of p38 in AR42J cells. Activation of p38 in AR42J was measured to determine whether the mitogen-activated protein kinase (MAPK) signaling pathway was involved in curcumin-mediated apoptosis. The ratio of phosphorylated (p)-p38/total (t)-p38 in the Blank group was significantly lower compared with CR + LPS group, and the CR + LPS group had a significantly higher p-p38/t-p38 ratio compared with the CUR $10+C R+$ LPS group $(\mathrm{P}<0.01$; Fig. 4$)$. The change in the ratio suggests that the MAPK signaling pathway may be deactivated following treatment with curcumin in the AP cell model. 

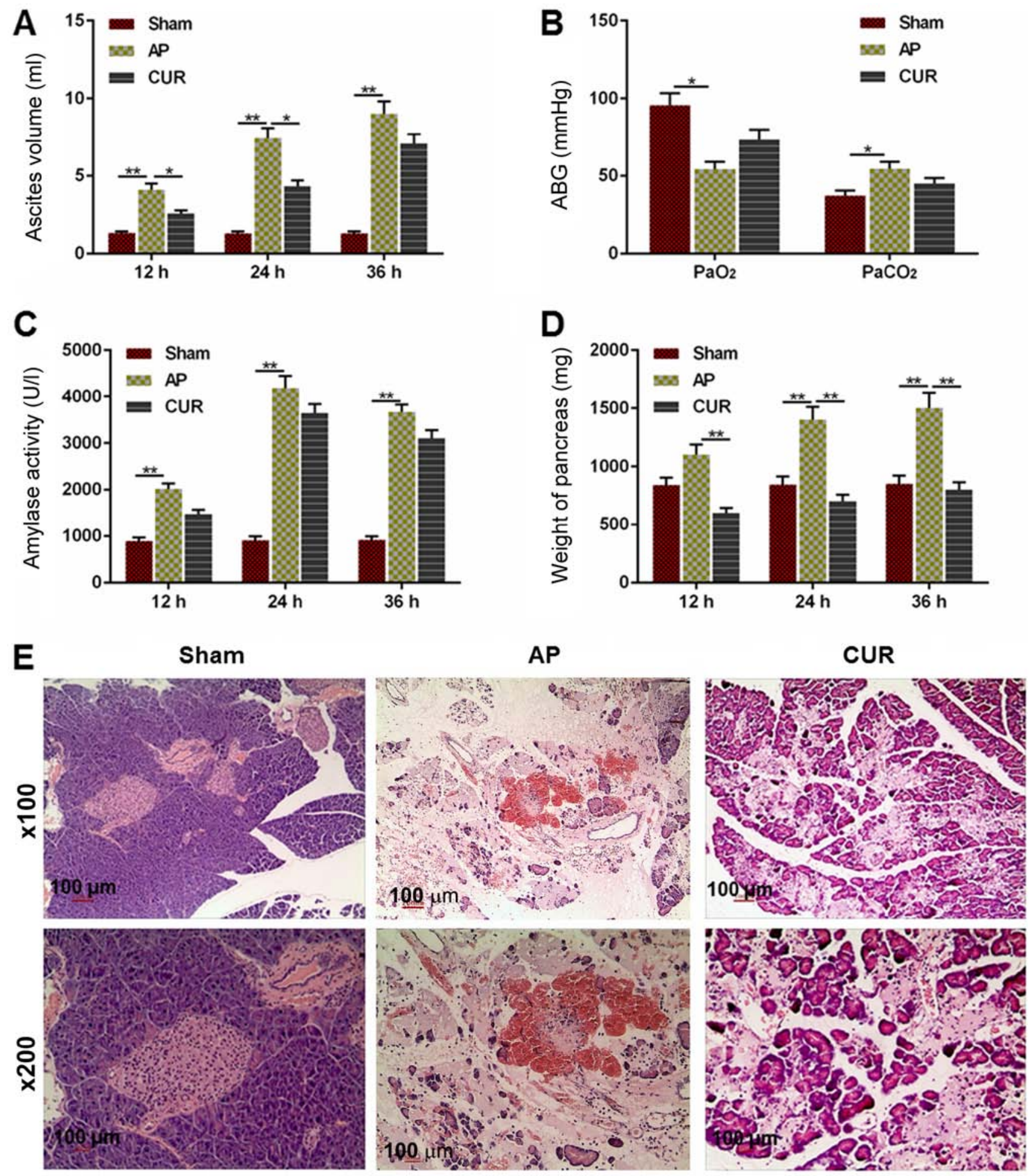

Figure 1. Extent of AP-induced damage in the Sham, AP and CUR groups. (A) Ascites volume in each group 12, 24 and $36 \mathrm{~h}$ after surgery. (B) ABG level $\left(\mathrm{PaO}_{2}\right.$ and $\left.\mathrm{PaCO}_{2}\right)$ in each group. (C) Amylase activity in each group at 12, 24 and $36 \mathrm{~h}$ after surgery. (D) Weight of the pancreas in each group at 12,24 and $36 \mathrm{~h}$ after surgery. (E) Hematoxylin and eosin staining of pancreatic tissue in each group at x100 and x200 magnification. ${ }^{*} \mathrm{P}<0.05,{ }^{* *} \mathrm{P}<0.01$. Sham, control; AP, acute pancreatitis; CUR, curcumin; ABG, arterial blood gas; Pa, partial pressure.

\section{Discussion}

In the present study, curcumin treatment reduced the severity of AP and the inflammatory response to AP in an AP animal model. Furthermore, the viability and amylase activity were also reduced in an acinar cell line when treated with curcumin. Therefore, deactivation of $\mathrm{p} 38$, the key molecule in the MAPK signaling pathway, may underlie the beneficial effect of curcumin on AP.

Ascites volume in the AP animal model was decreased when treated with curcumin at 12 and $24 \mathrm{~h}$ after surgery, and the weight of the pancreas was additionally reduced at 12, 24 and $36 \mathrm{~h}$ after surgery. In addition, pathologically, the degree of pancreatic injury was notably reduced when 

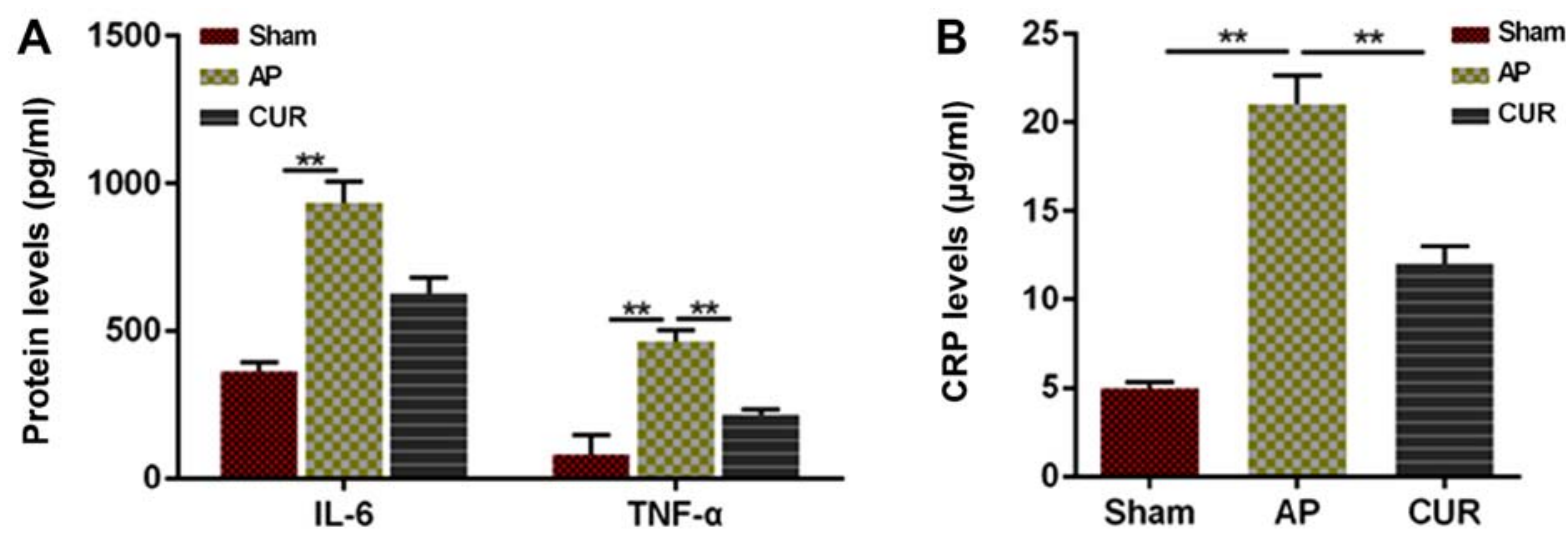

Figure 2. Level of IL-6, TNF- $\alpha$ and CRP in an animal model of acute pancreatitis. (A) Protein expression levels of IL-6 and TNF- $\alpha$ in each group. (B) CRP level in each group. ${ }^{* *} \mathrm{P}<0.01$. IL-6, interleukin 6; TNF- $\alpha$, tumor necrosis factor- $\alpha$; CRP, C-reactive protein; AP, acute pancreatitis; CUR, curcumin.
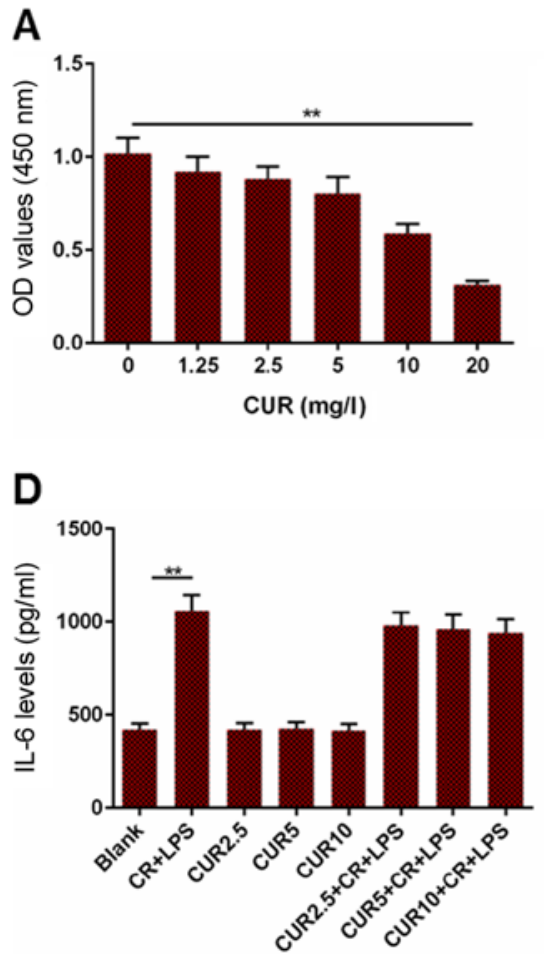

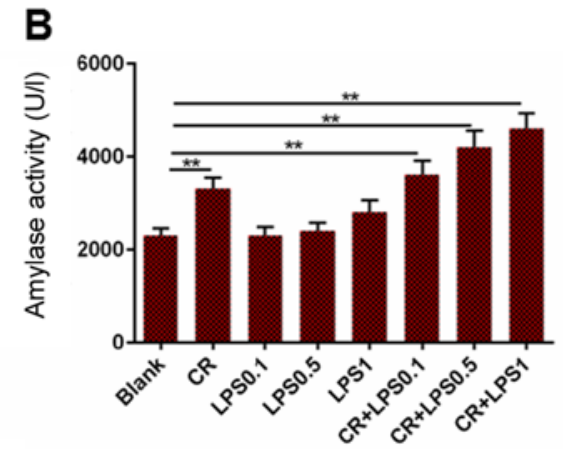

$\mathbf{E}$

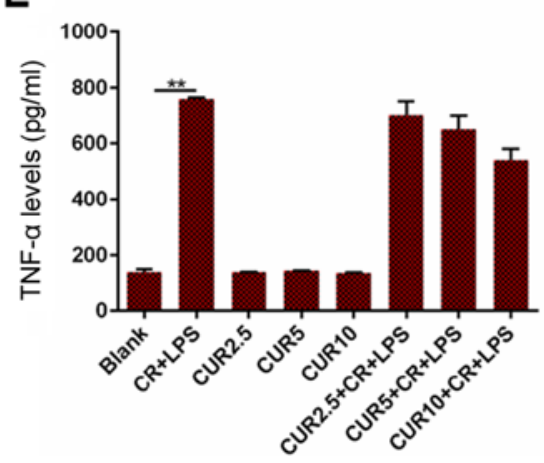

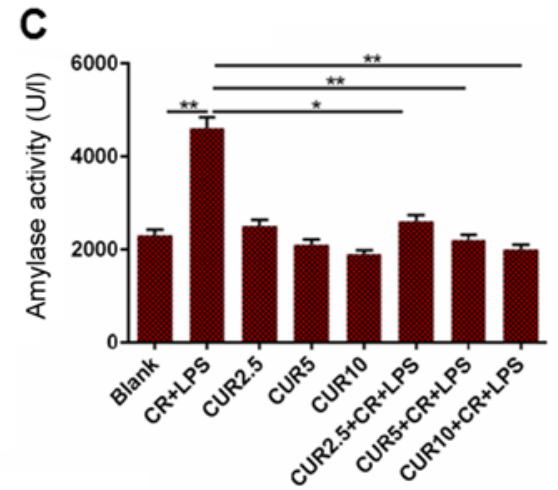

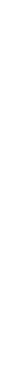

Figure 3. Measurement of cell viability, amylase activity, and levels of IL-6 and TNF- $\alpha$ in a cell model of AP. (A) OD values in cells treated with different concentrations of CUR. (B) Amylase activity in cells treated with different combinations CR and LPS to establish a cell model of AP. (C) Amylase activity in the cell model of AP treated with different concentrations of CUR. (D) IL-6 levels in the cell model of AP treated with different concentrations of CUR. (E) TNF- $\alpha$ levels in the cell model of AP treated with different concentrations of CUR. ${ }^{*} \mathrm{P}<0.05,{ }^{* *} \mathrm{P}<0.01$. IL-6, interleukin 6; TNF- $\alpha$, tumor necrosis factor- $\alpha$; OD, optical density; CUR, curcumin; CR, cerulein; LPS, lipopolysaccharide; AP, acute pancreatitis.

treated with curcumin. Curcumin treatment did not alter the ABG or amylase activity in the animal model of AP. Dugernier et al (11) demonstrated that the concentration of pro-inflammatory factors in ascites was significantly higher compared with that in the lymph fluid and plasma, and this may underlie injury to the pancreas. Furthermore, the formation of ascites was closely associated with the prognosis of patients with AP (11). Therefore, the measurement of ascites may reflect the severity of AP indirectly. ABG is additionally closely associated with the prognosis of patients with AP (12), thus $\mathrm{PaO}_{2}$ and $\mathrm{PaCO}_{2}$ were considered important for assessing the severity of AP. Blood amylase activity is the first physiological indicator to be altered in acute pancreatitis, and may directly indicate the severity and therapeutic effect of AP (13). In the process of AP, the liquid in the pancreatic tissue is increased, which is an important hallmark of pathological changes in the pancreatic tissue (14). This buildup of fluid ultimately leads to edema of the cells (14). Therefore, the pancreatic weight is measured as an indication of the liquid contained in the pancreatic tissue (14). Based on the results of the present study, curcumin may somehow promote the metabolism or removal of fluid from the pancreatic tissue, resulting in a reduction of the ascites volume and pancreas weight, thereby preventing further damage to the pancreatic cells. However, curcumin may not regulate the activity of amylase and $\mathrm{ABG}$ in vivo. 
A

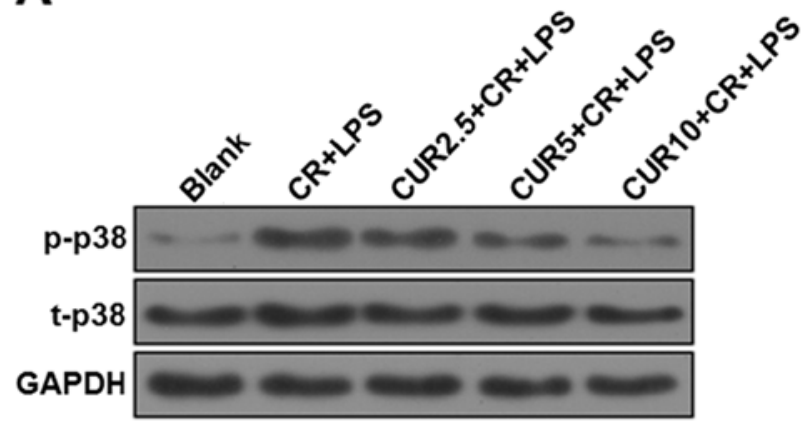

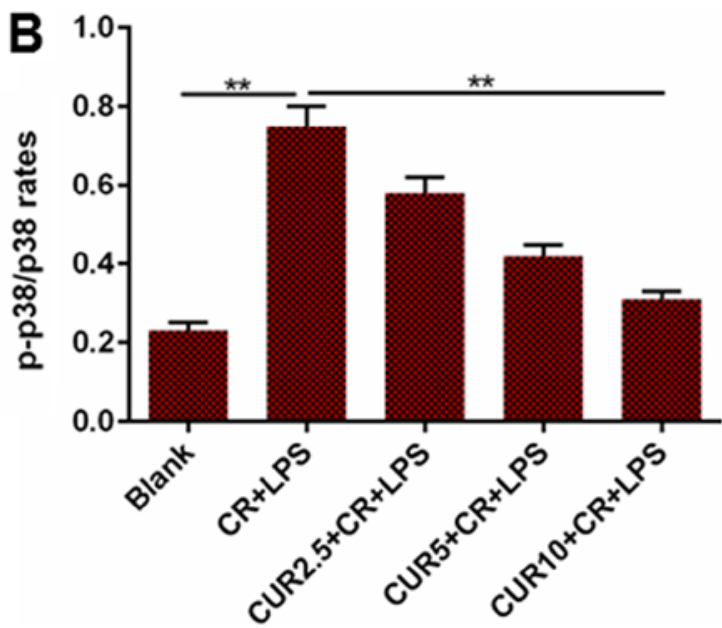

Figure 4. p-p38/t-p38 ratio in the cell model of AP treated with different concentrations of CUR. (A) Representative western blots of p-p38 and t-p38 expression in each group of AP model cells. (B) Densitometric analysis of the p-p38/t-p38 ratio in each group, normalized to GAPDH. ${ }^{* *} \mathrm{P}<0.01$. p, phosphorylated; $t$, total; AP, acute pancreatitis; CUR, curcumin; CR, cerulein; LPS, lipopolysaccharide.

TNF- $\alpha$ is secreted by activated macrophages and lymphocytes, and is a critical pro-inflammatory cytokine in the body $(15,16)$. It serves a role in initiating the development of AP by inducing the expression of IL-1, IL-6, IL-8 and other inflammatory markers, leading directly or indirectly to the uncontrolled release of the inflammatory mediators (5). IL-6 promotes the upregulation of neutrophil function and regulates the secretion of cytokines, adhesion molecules and inflammatory mediators such as nitric oxide, which are associated with the severity of AP $(5,17)$. CRP is a sensitive indicator of infectious and non-infectious inflammation (18). Normally, CRP serum levels are relatively low; however, when the body is experiences trauma or during an inflammatory response, CRP is an early indicator, upregulated during the earliest stages of the inflammatory response, and thus it is often used as an indicator for the detection of an inflammatory response in the body (18). In the AP animal model, TNF- $\alpha$ and CRP levels were downregulated by curcumin, whereas IL-6 was not. Zhong (19) demonstrated that curcumin had a protective effect in a rat model of severe AP, resulting in reduced TNF- $\alpha$ levels. Gulcubuk et al (20) demonstrated that curcumin markedly reduced serum TNF- $\alpha$ and IL- 6 levels in the late phase of AP, but did not prevent injury to the pancreatic tissue. Fisic et al (21) demonstrated that CRP was significantly increased and may be a valuable prognostic factor of the severity and systemic complications of AP. Based on these studies, curcumin may suppress the inflammatory response during the initial stages of inflammation in AP, to some extent.

Furthermore, curcumin decreased cell viability and downregulated amylase activity in the AP cell model. However, the levels of IL-6 and TNF- $\alpha$ were not significantly affected in this model. Bimonte et al (22) demonstrated that curcumin inhibited tumor growth in a mouse model of human pancreatic cancer (22). These results suggest the possibility that curcumin may decrease the cell viability of acinar cells in pancreatic tissues. There are numerous in vitro models of AP in acinar cells, the most frequently used of which was used in the present study (23-25), and it was demonstrated that $0.5 \mathrm{nM}$
CR in combination with $1 \mu \mathrm{g} / \mathrm{ml}$ LPS resulted in the largest increase in amylase activity, a critical hallmark of AP. Based on the results of the present study, $2.5,5$ and $10 \mathrm{mg} / \mathrm{l}$ curcumin (below the concentration that significantly deceased the cell viability) all significantly decreased amylase activity in the AP cell model compared with the control. Yu et al (26) additionally demonstrated that pretreatment with curcumin reduced the amylase activity in AP rats as well as the levels of IL-6 and TNF- $\alpha$. This suggests the possibility that other factors may exist in pancreatic tissue that affect the activity of curcumin in AP. Therefore, the mechanism underlying the activity of curcumin in vitro compared with in vivo in models of AP require further study.

Phosphorylation of p38 was when cells were treated with curcumin in the AP cell model, suggesting that the MAPK signaling pathway was deactivated by curcumin. The MAPK signaling pathway is a ubiquitous signaling pathway in eukaryotic cells and includes proteins that belong to the serine/threonine protein kinase family. This family consists of three primary types of proteins: p38 MAPK, c-Jun $\mathrm{N}$-terminal kinase (JNK) and extracellular regulated protein kinases (ERKs) (27). p38 MAPK is a stress-responsive MAPK and is a pivotal protein during intracellular signal transduction (28). p38 MAPK participates in the regulation of various physiological and pathophysiological processes, including cell differentiation, proliferation, migration and apoptosis (28). Inflammatory factors such as IL-1 $\beta$ and TNF- $\alpha$ activate the p38 MAPK signaling pathway by inducing activation of macrophages to promote apoptosis of tissue cells $(29,30)$. Phosphorylation of p38 MAPK promotes the activation of NF- $\kappa B$ and its translocation to the nuclear domain, thereby stimulating the synthesis of inflammatory factors such as TNF- $\alpha(29,31)$. However, it stills remains to be determined which specific regulatory pathway is affected by curcumin treatment, and whether the same pathway is affected both in vitro and in vivo.

In conclusion curcumin may lower the severity of the inflammatory response via the MAPK signal pathway, to some extent, in in vitro and in vivo models of AP. Further studies 
are required to elucidate the specific underlying mechanisms regulated by curcumin treatment. However, the present study highlighted the therapeutic potential of curcumin for treating AP.

\section{Acknowledgements}

Not applicable.

\section{Funding}

No funding was received.

\section{Availability of data and materials}

The datasets used and/or analyzed during the present study are available from the corresponding author on reasonable request.

\section{Authors' contributions}

YW and CB conceived and designed the study. KW, RW and JW acquired and interpreted the data. KW and JW drafted the manuscript and critically revised and added important intellectual content. The final version of the manuscript has been read and approved by all of the authors. All authors agree to be accountable for all aspects of the work, ensuring that questions related to the accuracy or integrity of the work are appropriately investigated and resolved.

\section{Ethics approval and consent to participate}

The present study was approved by The Ethical Board of Qilu Hospital of Shandong University.

\section{Patient consent for publication}

Not applicable.

\section{Competing interests}

The authors declare that they have no competing interests.

\section{References}

1. Golay V and Roychowdhary A: Acute pancreatitis in chronic kidney disease-a common but often misunderstood combination. Ren Fail 34: 1338-1340, 2012.

2. Cavestro GM, Leandro G, Di Leo M, Zuppardo RA, Morrow OB, Notaristefano C, Rossi G, Testoni SG, Mazzoleni G, Alessandri M, et al: A single-centre prospective, cohort study of the natural history of acute pancreatitis. Dig Liver Dis 47 205-210, 2015.

3. Okuturlar Y, Soylu A, Dogan H, Cakmak S, Kirac Utku I, Oztosun B, Akarsu C, Ocak Serin S, Avci A, Kones O, et al: Mean platelet volume in patients with biliary and non-biliary acute pancreatitis. Int J Clin Exp Pathol 8: 2051-2056, 2015.

4. Albulushi A, Siddiqi A, Alqarshoubi I, Aladawi M, Alkhadhouri G and Farhan H: Pattern of acute pancreatitis in a tertiary care center in oman. Oman Med J 29: 358-361, 2014.

5. Dabrowski A, Osada J, Dabrowska MI, WereszczynskaSiemiatkowska U and Siemiatkowski A: Increased expression of the intercellular adhesion molecule-1 (ICAM-1) on peripheral blood neutrophils in acute pancreatitis. Adv Med Sci 59: 102-107, 2014.
6. Shen SQ, Zhang Y, Xiang JJ and Xiong CL: Protective effect of curcumin against liver warm ischemia/reperfusion injury in rat model is associated with regulation of heat shock protein and antioxidant enzymes. World J Gastroenterol 13: 1953-1961, 2007.

7. Jurenka JS: Anti-inflammatory properties of curcumin, a major constituent of Curcuma longa: A review of preclinical and clinical research. Altern Med Rev 14: 141-153, 2009.

8. Anchi P, Khurana A, Swain D, Samanthula G and Godugu C: Sustained-release curcumin microparticles for effective prophylactic treatment of exocrine dysfunction of pancreas: A preclinical study on cerulein-induced acute pancreatitis. J Pharm Sci 107: 2869-2882, 2018.

9. Zhu S, Zhang C, Weng Q and Ye B: Curcumin protects against acute renal injury by suppressing JAK2/STAT3 pathway in severe acute pancreatitis in rats. Exp Ther Med 14: 1669-1674, 2017.

10. Zhai KF, Duan H, Khan GJ, Xu H, Han FK, Cao WG, Gao GZ, Shan LL and Wei ZJ: Salicin from alangium chinense ameliorates rheumatoid arthritis by modulating the Nrf2-HO-1-ROS pathways. J Agric Food Chem 66: 6073-6082, 2018.

11. Dugernier TL, Laterre PF, Wittebole X, Roeseler J, Latinne D, Reynaert MS and Pugin J: Compartmentalization of the inflammatory response during acute pancreatitis: Correlation with local and systemic complications. Am J Respir Crit Care Med 168: 148-157, 2003.

12. Polyzogopoulou E, Bikas C, Danikas D, Koutras A, Kalfarentzos F and Gogos CA: Baseline hypoxemia as a prognostic marker for pulmonary complications and outcome in patients with acute pancreatitis. Dig Dis Sci 49: 150-154, 2004.

13. Cöl C, Dinler K, Hasdemir AO and Bugdayci G: The effect of an intraperitoneal injection of melatonin on serum amylase levels in acute pancreatitis. JOP 10: 306-309, 2009.

14. Bonior J, Warzecha Z, Ceranowicz P, Gajdosz R, Pierzchalski P, Kot M, Leja-Szpak A, Nawrot-Porąbka K, Link-Lenczowski P, Pędziwiatr M, et al: Capsaicin-sensitive sensory nerves are necessary for the protective effect of ghrelin in cerulein-induced acute pancreatitis in rats. Int J Mol Sci 18: pii: E1402, 2017.

15. Bishehsari F, Sharma A, Stello K, Toth C, O'Connell MR, Evans AC, LaRusch J, Muddana V, Papachristou GI and Whitcomb DC: TNF-alpha gene (TNFA) variants increase risk for multi-organ dysfunction syndrome (MODS) in acute pancreatitis. Pancreatology 12: 113-118, 2012.

16. Malleo G, Mazzon E, Siriwardena AK and Cuzzocrea S: Role of tumor necrosis factor-alpha in acute pancreatitis: From biological basis to clinical evidence. Shock 28: 130-140, 2007.

17. Culić O, Eraković V, Cepelak I, Barisić K, Brajsa K, Ferencić Z, Galović R, Glojnarić I, Manojlović Z, Munić V, et al: Azithromycin modulates neutrophil function and circulating inflammatory mediators in healthy human subjects. Eur J Pharmacol 450: 277-289, 2002.

18. Bezmarevic M, Mirkovic D, Soldatovic I, Stamenkovic D, Mitrovic N, Perisic N, Marjanovic I, Mickovic S and Karanikolas M: Correlation between procalcitonin and intra-abdominal pressure and their role in prediction of the severity of acute pancreatitis. Pancreatology 12: 337-343, 2012.

19. Zhong K: Curcumin Mediates a Protective effect via TLR-4/NF- $\kappa \mathrm{B}$ signaling pathway in rat model of severe acute pancreatitis. Cell Biochem Biophys 73: 175-180, 2015.

20. Gulcubuk A, Altunatmaz K, Sonmez K, Haktanir-Yatkin D, Uzun H, Gurel A and Aydin S: Effects of curcumin on tumour necrosis factor-alpha and interleukin- 6 in the late phase of experimental acute pancreatitis. J Vet Med A Physiol Pathol Clin Med 53: 49-54, 2006.

21. Fisic E, Poropat G, Bilic-Zulle L, Licul V, Milic S and Stimac D: The role of IL-6, 8, and 10, sTNFr, CRP, and pancreatic elastase in the prediction of systemic complications in patients with acute pancreatitis. Gastroenterol Res Pract 2013: 282645, 2013.

22. Bimonte S, Barbieri A, Palma G, Luciano A, Rea D and Arra C: Curcumin inhibits tumor growth and angiogenesis in an orthotopic mouse model of human pancreatic cancer. Biomed Res Int 2013: 810423, 2013.

23. Qin T, Fu Q, Pan YF, Liu CJ, Wang YZ, Hu MX, Tang Q and Zhang HW: Expressions of miR-22 and miR-135a in acute pancreatitis. J Huazhong Univ Sci Technolog Med Sci 34: 225-233, 2014.

24. Patel K, Durgampudi C, Noel P, Trivedi RN, de Oliveira C and Singh VP: Fatty acid ethyl esters are less toxic than their parent fatty acids generated during acute pancreatitis. Am J Pathol 186: 874-884, 2016.

25. Talukdar R, Sareen A, Zhu H, Yuan Z, Dixit A, Cheema H, George J, Barlass U, Sah R, Garg SK, et al: Release of cathepsin $b$ in cytosol causes cell death in acute pancreatitis. Gastroenterology 151: 747-758.e5, 2016. 
26. Yu S, Wang M, Guo X and Qin R: Curcumin attenuates inflammation in a severe acute pancreatitis animal model by regulating TRAF1/ASK1 signaling. Med Sci Monit 24: 2280-2286, 2018.

27. Samuel I, Zaheer A and Fisher RA: In vitro evidence for role of ERK, p38, and JNK in exocrine pancreatic cytokine production. J Gastrointest Surg 10: 1376-1383, 2006.

28. Chen P, Huang L, Zhang Y, Qiao M and Yuan Y: SiRNA-mediated PIAS1 silencing promotes inflammatory response and leads to injury of cerulein-stimulated pancreatic acinar cells via regulation of the P38MAPK signaling pathway. Int J Mol Med 26: 619-626, 2010.

29. Kim D and Haynes CL: The role of p38 MAPK in neutrophil functions: Single cell chemotaxis and surface marker expression. Analyst 138: 6826-6833, 2013.
30. Kim HA, Kim KJ, Seo KH, Lee HK and Im SY: PTEN/MAPK pathways play a key role in platelet-activating factor-induced experimental pulmonary tumor metastasis. FEBS Lett 586: 4296-4302, 2012.

31. Lee SJ, Kim WJ and Moon SK: Role of the p38 MAPK signaling pathway in mediating interleukin-28A-induced migration of UMUC-3 cells. Int J Mol Med 30: 945-952, 2012.

(i) (9) This work is licensed under a Creative Commons Attribution-NonCommercial-NoDerivatives 4.0 International (CC BY-NC-ND 4.0) License. 